\title{
Rémi LOPEZ: The Impact of Akira: A Manga [R]evolution
}

\author{
Martin DE LA IGLESLA
}

(2020. Translated by Jennifer Ligas. Toulouse:

Third Éditions, pp. 192. ISBN: 2377842801 (ISBN13: 9782377842803))

An English-language monograph about an individual manga title is still a rarity. Only Julian Darius's little booklet on Mai, the Psychic Girl comes to mind (Darius 2014), and apparently another book by Third Éditions, on the late Miura Kentarōs Berserk, has recently been published (Boëton 2020). With regard to Ōtomo Katsuhiro's Akira, there is also Akira Club (Ōtomo 2007), which amounts to an official handbook (and which was also one of Rémi Lopez's sources for The Impact of Akira). This dearth of books published about Akira in the almost four decades after the beginning of its serialization would be surprising if we took at face value Lopez's statements that "[i]t is widely agreed that Akira divided the world of manga into a before and an after" (Lopez 2020,7) and that "Akira would revolutionize the manga genre, creating a demand for Japanese comics that extended well beyond the country's borders" (ibid., 38). In fact, the precise impact that Akira had is a matter of debate-some earlier and later manga titles are often said to have been more decisive in the development of the art-and it is not a trivial task to assess that impact. ${ }^{1}$ Despite the title of the book in question being The Impact of Akira, however, Lopez is not actually concerned with the reception of this man$\mathrm{ga}$, neither domestically nor overseas.

What then is this book about? Basically it is divided into two parts, the first shorter one titled "Creation" (ibid., 9-80), and the longer second one "Creature" (ibid., 81-200). The former is an extensive biography of Ōtomo. Sub-divided into three chapters (before, during, and after the creation of Akira), it describes in astounding detail all of the shorter manga works and other projects Ōtomo created besides Akira. It also becomes clear that Lopez's subject is not only Akira the manga, as the subtitle $A$ Manga [R]evolution would imply, but also its anime adaptation

1 A scholarly investigation of Akira's reception in the Western world is part of de la Iglesia (2020).

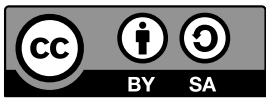


from 1988 directed by Ōtomo himself, and throughout the book it is sometimes difficult to tell which of these two different works Lopez is referring to. In this first part of the book, it would also have been helpful to Lopez's non-Japanese speaking target audience if he had included a bibliography of Ötomo's works that have been translated into English, as some of them have become rare collector's items that are hard to track down.

From a scholarly perspective, it is also noticeable that while Lopez relays many bits of obscure information, fascinating anecdotes, and direct quotations from Ötomo, he uses very few footnotes in his book, and those that do appear do not always contain references to the sources of his information. The bibliography at the end of the book supplies some more sources, but it is difficult for the reader to figure out which bibliography item was the source of which piece of information. Several published interviews are listed which are most likely the source for the numerous Ötomo quotations, ${ }^{2}$ so strictly speaking there is no original research informing The Impact of Akira. Even if the lack of references makes clear that the book is not a scholarly text, there is still a wealth of information in it that might prove useful to researchers, provided they are ready to do the work and verify each of the "statements" given.

In contrast to the first part of the book, the second is rather problematic. Each of its eight chapters is structured in the same way: a purported theme in Akira is identified-e.g. World War II, the body and sexuality, the "(New) New Religions" / (shin-)shinshükyo, etc. - and then this theme is traced through Japanese cultural history. There are two main problems with this approach. The first is that Lopez's forays into the history of a certain motif, while demonstrating his impressively deep and wide knowledge of Japanese and international (mostly popular) culture, are rarely connected back to Akira. For instance, Lopez discusses (in the context of the topic of war) at some length the anime series $U_{c h} \bar{u}$ Senkan Yamato from 1974 (Lopez 2020, 90-92), or (regarding the theme of fictional post-apocalyptic cults) the live-action film Mad Max: Fury Road from 2015 (ibid., 176) — but why? What is the relation between those two works and the actual subject of his book, Akira? Does Lopez want to say that Uchü Senkan Yamato inspired Akira, or that Fury Road was inspired by Akira? If so, why does he not explicitly say this?

The other problem in the "Creature" part of the book is that any identification of a motif in a text is a matter of debate, and the merit of such an interpretation

2 Furthermore, much of what Lopez says about the production of Akira the anime (51-62) is obviously based on the official making-of video Akira Production Report, which was widely circulated on VHS and DVD (and also on YouTube, according to Lopez's bibliography). 
relies on how convincingly the author makes a case for each such claim. If the reader does not agree with one of Lopez's readings, anything else he writes on that particular topic becomes dubious. In chapter 2.1, for example, Lopez spots the "A-Bomb Specter" haunting Akira: "Otomo has never explicitly referred to the obvious juxtaposition between his work and the scars inflicted by the events of August 1945; he really didn't need to" (ibid., 82). Is this juxtaposition really that obvious though? Of course, the idea that the fictional cataclysmic explosions in Akira (particularly the one in the flashback at the beginning of both the manga and the anime) can be compared to the atomic bombings of Hiroshima and Nagasaki in 1945 is nothing new. ${ }^{3}$ However, the explosions caused by Akira are certainly not nuclear ones; they are psychic, supernatural, "a new kind of bomb" (shingata bakudan 新型爆弾), as it says on the very first page of the manga. This distinction is important as there are in fact actual nuclear explosions depicted in the manga, near the end of the 5th volume in the six-volume edition when Tetsuo seizes control of the nuclear missile launchers of the aircraft carrier-with mushroom clouds and all. This often overlooked scene would have merited a close reading and a comparison to those featuring psychic explosions, as this would have put in perspective the facile equating of the latter with the real-world historical bombings in WWII.

More straightforward is the identification of the motorcycle gang phenomenon called bōsozoku phenomenon as a trope that informs Akira, although one wonders why Lopez discusses it primarily in connection with Kaneda's gang ("known as the Capsules"(ibid., 108)) and not their decidedly more flamboyant rival gang, the Clowns. Regarding the so-called Capsules, Lopez admits later in the book that this gang is only "unofficially dubbed the "Capsules" (ibid., 165)-i.e. neither in the manga nor in the anime are they given a name- but then reads too much into this extratextual designation when he writes about Tetsuo's need to "recognize and accept his addiction to 'Capsules' (both the bikers and the drugs)" (ibid., 165).

There is an overall tendency in The Impact of Akira towards interpretations that are more arbitrary than compelling. "Many parallels can be drawn" (ibid., 155) between Akira and more or less any topic, but do those parallels really need to be drawn? In his chapter on cyberpunk (2.4), Lopez wriggles out of giving a proper definition of this genre, instead listing a wide array of possible cyberpunk tropes, and then saying that "cyberpunk works aren't required to tackle all of the above" (ibid., 143) - which conveniently allows Akira to be placed in the cyberpunk genre. Actually the relation between Akira and cyberpunk is far more complex than

3 E.g. perhaps most prominently in Bolton (2014): "To see Akira in the United States in 1990 was to be transported back in history to the moment of Hiroshima [...]." 
this suggests, and it is a pity that Lopez has apparently not taken notice of the published research regarding precisely this question (de la Iglesia 2018). ${ }^{4}$

"So, what are we to make of Akira?", Lopez asks in the Conclusion; "what's it all about? [...] Akira's complexity prevents it from being fully grasped” (ibid., 197). Is this really the question that readers bring to this manga, though? Do they need a book to help them understand what it is all about? Perhaps they would rather learn more about the creation of Akira, and about its creator Ōtomo, and this is what (the first part of) The Impact of Akira achieves quite well. As for the second part of the book, Akira definitely is a complex work full of mysteries that might puzzle many a (Western) reader, and these indeed require (or would at least benefit from) deeper exploration and explication by someone with-possibly even Japanological-expertise. I am thinking of, for example, the mode of speaking of the character known as the "Rhymester" (who, in the English translation, speaks in rhymes), or the malapropisms in Yamagata's speech, or the ghostly apparitions of Kaneda and Kei which seem to be visions of the future, but not quite.

Finally, two more things about The Impact of Akira are worth mentioning. One is the complete lack of illustrations inside the book: the stunning cover illustration by Guillaume Singelin might give the false impression of a lavishly illustrated coffee-table book, but in fact it contains no images whatsoever. The other is that this shortcoming is to some extent made up for by the great readability of the text, as the translation from French by Jennifer Ligas is almost flawless, ${ }^{5}$ and the result is a work of elegant prose. To sum up, this book might not be a "must-read" from a scholarly perspective, but for those just beginning to explore Ōtomo's manga, it might serve as a starting point for further research.

\section{References}

Boëton, Quentin. 2020. Berserk. Written in Darkness. Translated by Michael Ross. Toulouse: Third Éditions.

Bolton, Christopher. 2014. "From Ground Zero to Degree Zero. Akira from Origin to Oblivion." Mechademia 9: 295-315.

4 Another relevant text that came out too late to be considered by Lopez is de la Iglesia and Schmeink (2020).

5 One of the few obvious errors is the translation of what must have originally been "planches de dessinées" as "panel illustrations" in the sentence: "In fact, 1980 was his [i.e. Ötomo's] most productive year in terms of panel illustrations, as he published a total of 553!” (Lopez 2020, 39). Surely the meaning here is pages, not panels. 
Darius, Julian. 2014. When Manga Came to America. Super-Hero Revisionism in Mai, the Psychic Girl. Edwardsville: Sequart.

De la Iglesia, Martin. 2018. "Has Akira Always Been a Cyberpunk Comic?" Arts 7 (3). https://doi.org/10.3390/arts7030032.

.2020. "The Early Reception of Manga in the West." PhD diss., Heidelberg University.

De la Iglesia, Martin, and Lars Schmeink. 2020. "Akira and Ghost in the Shell (Case Study)." In The Routledge Companion to Cyberpunk Culture, edited by Anna McFarlane, Graham J. Murphy and Lars Schmeink, 162-68. New York, London: Routledge.

Ōtomo, Katsuhiro. 2007. Akira Club. Translated by Kumar Sivasubramanian. London: Titan. 